\title{
Synchronization of Traffic Light Systems for Maximum Efficiency along Jalan Bukit Gambier, Penang, Malaysia
}

\author{
M.A. Ahmad Rafidi ${ }^{1}$, A.H. Abdul Hamid ${ }^{2, a}$ \\ ${ }^{1,2}$ School of Housing, Building and Planning, Universiti Sains Malaysia, 11800, Penang, Malaysia
}

\begin{abstract}
The synchronization of traffic light systems is one of the best solutions in order to avoid problematic traffic jams. Traffic timing is a major concern when it comes to traffic management. One of the common causes of traffic jams is because of nonsynchronized traffic light systems. Once a light turns green, traffic begins to move, but by the time the moving traffic reaches the next light, the signal is still red. This will disrupt the continuity of the traffic flow, especially for large main roads. The smooth flow of traffic on main routes is important to clear dense traffic in a given time. This study examined the density of vehicles on Jalan Bukit Gambier and also the traffic timing was documented in order to plan out proper re-timing for traffic lights along the studied road. The outcomes of this study support the hypothesis that retiming traffic lights to create a synchronized traffic light system for main roads will greatly improve traffic flow.
\end{abstract}

\section{Introduction}

Traffic congestion in urban areas is a common problem faced by urban workers. A hectic day needs to be compensated for by arriving home as soon as possible. However, traffic congestion is a major issue preventing people from getting where they need to go in a reasonable amount of time. The greatest problem that causes traffic congestion is inefficiency of traffic light systems or traffic management. Research on this current problem is needed in order to prevent traffic congestion, especially during peak times. The purpose of this research is to compare unsynchronized and synchronized traffic light systems in order to prove that the synchronization of traffic light systems will solve traffic problems and help to achieve maximum efficiency. This research took the form of a case study which focused on urban areas that currently apply a synchronized system and drew a comparison with urban areas that do not apply such a system.

There are a lot of software programs that can be used to retime traffic systems in order to make sure roads can be clear in time. This method (synchronization) is commonly used for straight traffic, but it can be a challenge for urban areas with a high number of traffic lights. Furthermore, there were a number of methods that needed to be applied in this study to arrive at the best outcomes.

The hypothesis of this study was that an improved traffic light system will lead to better traffic management and, therefore, more peaceful urban areas. As traffic is a fickle system, small changes in traffic systems will have big impacts on traffic flow. Overall, the goal of this study is to improve Malaysia's traffic system by implementing small but dynamic changes, thus benefiting road users' driving experience and cutting down on unnecessary wait time on roads.

\footnotetext{
${ }^{\mathrm{a}}$ Corresponding author : hilcom@usm.my
} 


\section{Materials and Survey}

\subsection{Jalan Bukit Gambier}

The survey was done along Jalan Bukit Gambier which is $4.6 \mathrm{~km}$ long. It runs from the junction of Lorong Bukit Gambier 1 on one end to the junction of Jalan Tun Dr Awang. Figure 1 shows the course of Jalan Bukit Gambier.
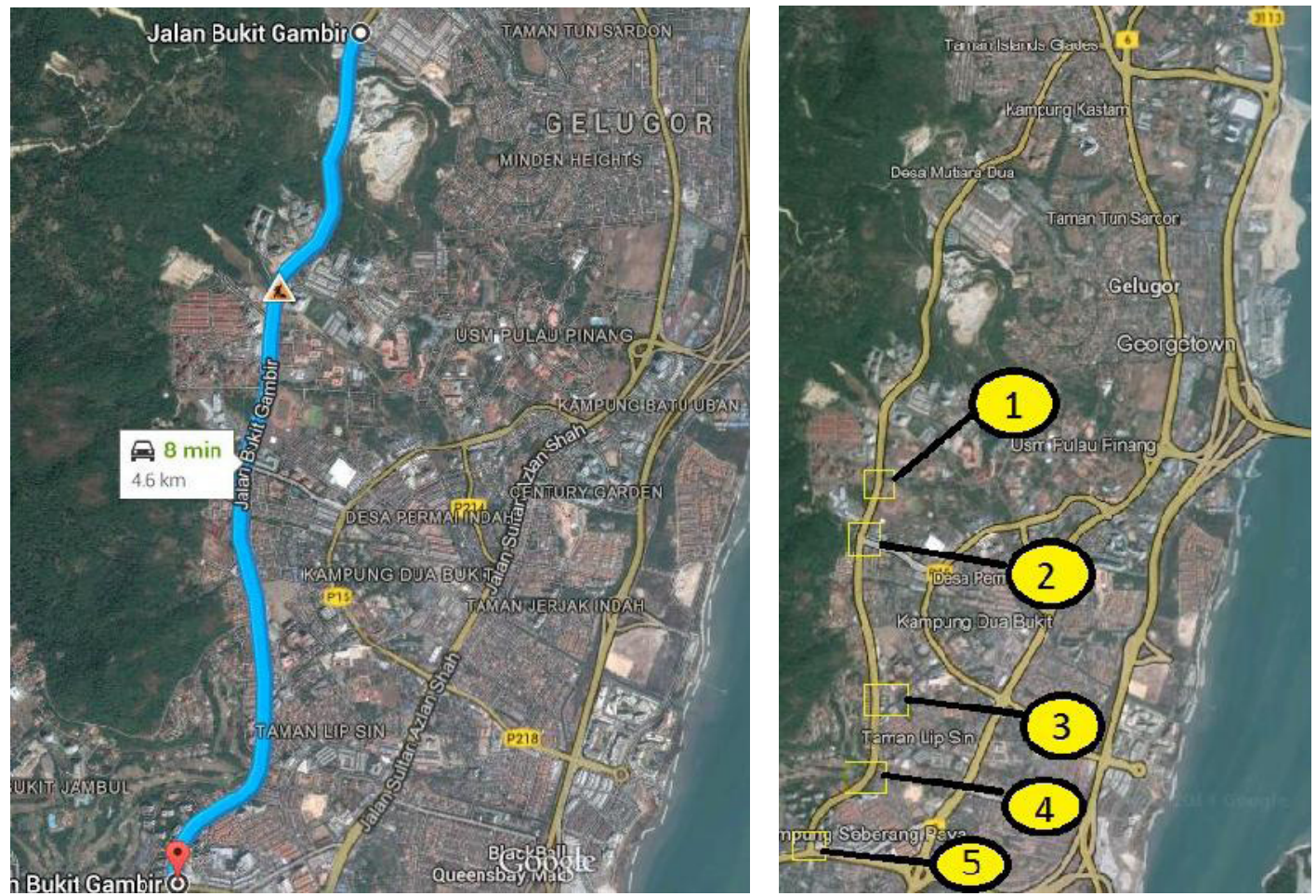

Fig 1: Route of Jalan Bukit Gambier

Fig 2: Location of traffic lights

\subsection{Junctions}

There are five (5) stops along Jalan Bukit Gambier. The only four-way junction is the one at Universiti Sains Malaysia (RST) which is Junction No1. The rest are T-junctions or three-way junctions. Figure 2 shows the location of each intersection along Jalan Bukit Gambier. Each traffic light location has it owns importance in terms of distance between the other traffic lights.

\subsection{Video Taping}

This survey was taken by videotaping activity at the selected intersections. This was done in order to capture the moment of each junction when the lights turned green. Doing so proved to be the best method for showing how synchronized traffic lights work and also to demonstrate the significance of using a synchronizes traffic light system for road users, especially for workers going to work in the morning and coming back in the evening.

\section{Survey Setup}

As mentioned, research was done by videotaping along the $4.6 \mathrm{~km}$ route. Observations were made only during the peak hours of 8:00 a.m. to $8: 30 \mathrm{a} . \mathrm{m}$. in the morning, 1:00 p.m. to 1:30 p.m. in the afternoon, and 6:00 p.m. to 6:30 p.m. in the evening. Table 1 shows the observation schedule. 
Table 1: Observation Schedule

\begin{tabular}{|c|l|l|l|}
\hline Monday & $8: 00$ a.m. & $1: 05$ p.m. & $6: 05$ p.m. \\
\hline Tuesday & $8: 15$ a.m. & $1: 20$ p.m. & $6: 00$ p.m. \\
\hline Wednesday & $8: 15$ a.m. & $1: 10$ p.m. & $6: 00$ p.m. \\
\hline Thursday & $8: 20$ a.m. & $1: 00$ p.m. & $6: 20$ p.m. \\
\hline Friday & $8: 05$ a.m. & $1: 20$ p.m. & $6: 05$ p.m. \\
\hline Saturday & $8: 00$ a.m. & $1: 15$ p.m. & $6: 00$ p.m. \\
\hline Sunday & $8: 26$ a.m. & $1: 00$ p.m. & $6: 00$ p.m. \\
\hline
\end{tabular}

\section{Results and Discussion}

Figure 3 shows the density of vehicles on the road on given days. The survey shows that the densest traffic was on Monday, Wednesday and Friday. These three days were considered to have the densest traffic because the traffic could not be cleared within the timespan of one green light.

Such traffic blockage was evident on the road in front of RST Universiti Sains Malaysia, where traffic was also being videotaped. Even after a three minute green light on such a large, main road, traffic still could not clear out. Because the traffic could not be cleared in the time given, it was assumes that the density of traffic on Monday, Wednesday and Friday was doubled the normal rate.

\section{5}

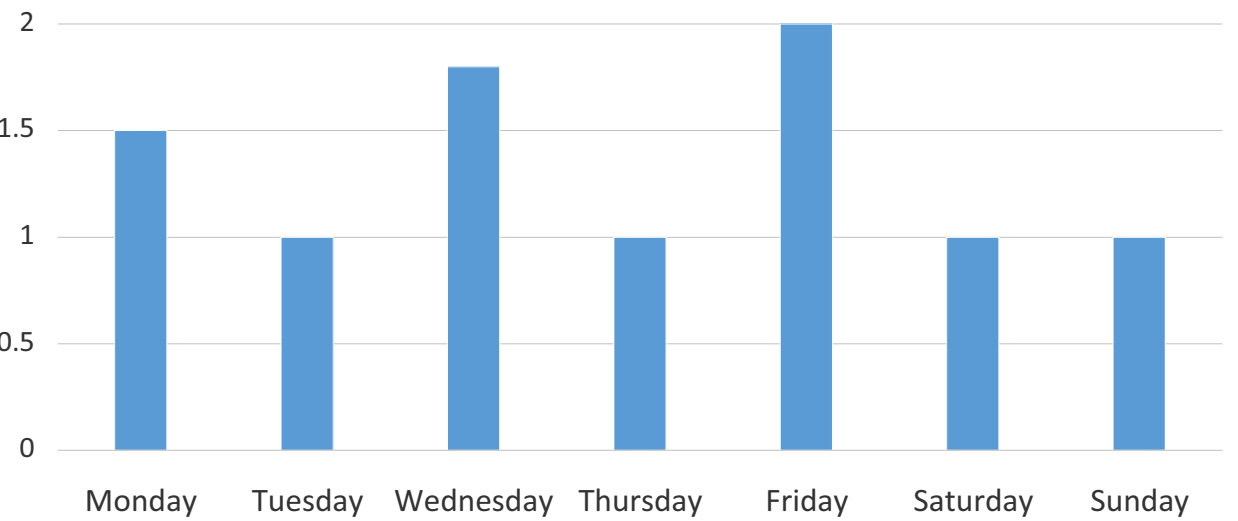

Figure 3. Density of Vehicles

The value of on the left side of the graph indicates the ability of traffic to clear out of the intersection in time. The lower the value, the better the road is at being cleared in the given time. On the other hand, a higher value means traffic is worse, not allowing vehicles to be cleared with a number of vehicles continuously waiting to move forward. The optimum value is one (1) which indicates that the exact amount of vehicles can be cleared in a time given. The traffic lights at USM (RST) and Bukit Jambul junctions allowed three minutes per green light while the other traffic junctions were set at one minute intervals for the peak hours (Table 2).

Table 2: Green Light Time

\begin{tabular}{|c|c|}
\hline Traffic Light & Green Light Time \\
\hline Traffic 1 & 3minutes \\
\hline Traffic 2 & 1minute \\
\hline Traffic 3 & 1minute \\
\hline Traffic 4 & 1minute \\
\hline Traffic 5 & 3minutes \\
\hline
\end{tabular}


Most importantly, the distance between traffic lights as well as the time taken for a vehicle to reach the next traffic light must be taken into consideration. The following are the details for each traffic light along Jalan Bukit Gambier (Table 3).

Table 3: Traffic Light Details

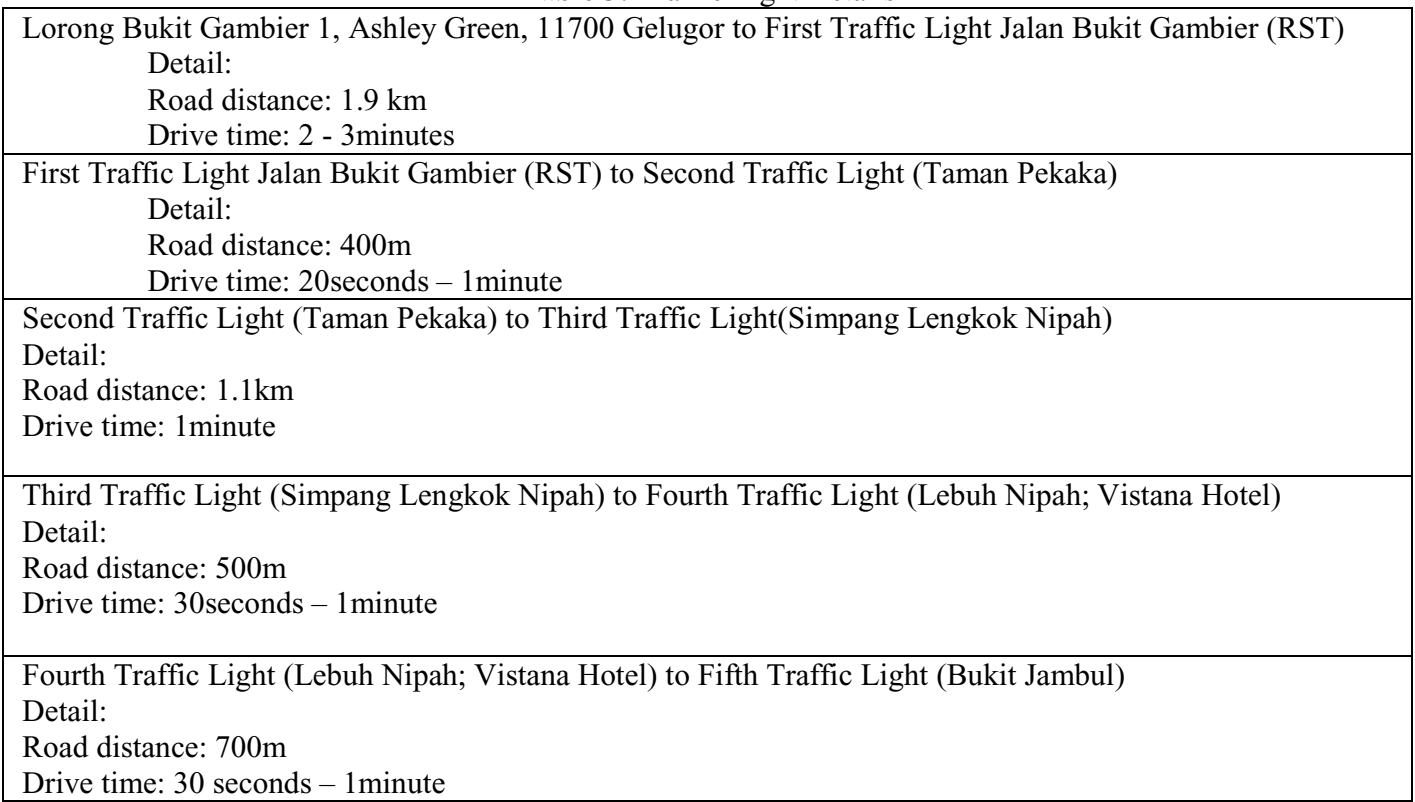

Traffic only flows continuously from Junction Taman Pekaka to Junction Bukit Jambul. So, the traffic from USM halts the flow of traffic, causing vehicles to get stuck at the Taman Pekaka traffic light following the green light at the RST junction. Huge amounts of vehicles then need to wait for traffic at Taman Pekaka. The disruption to the flow of traffic points to the need to retime the current traffic light system.

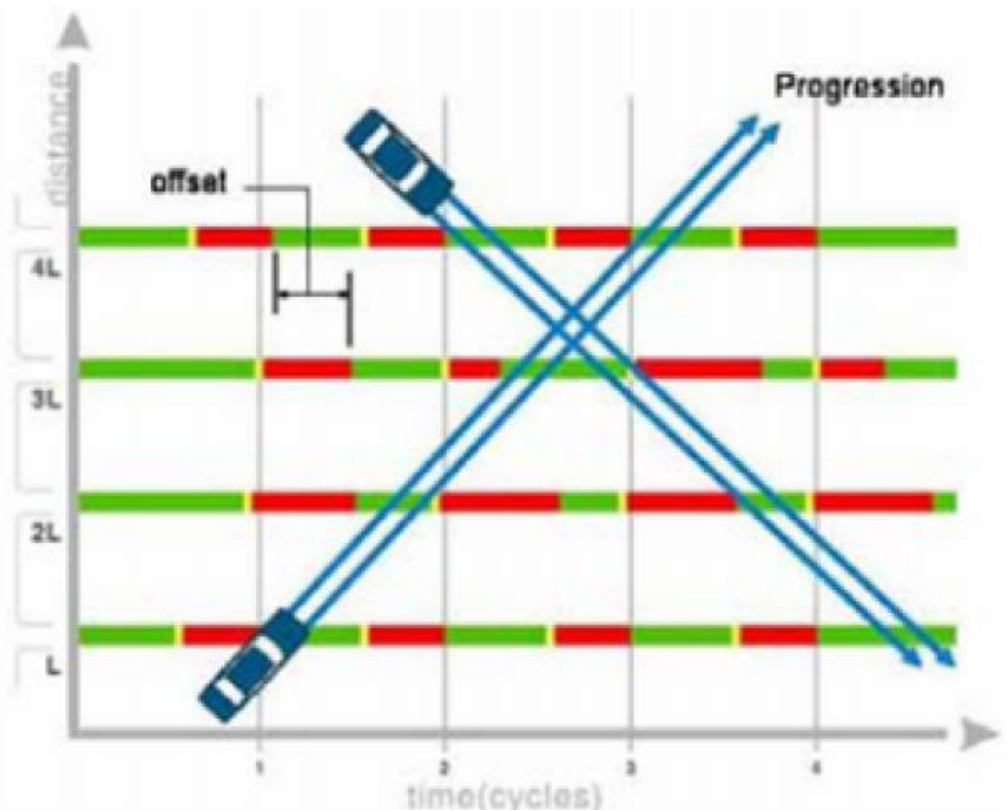

Figure 4. Traffic Offset System 
By using an offset traffic light system continuity in traffic lights could be achieved. An offset system works based on the time between the start of the green light at one junction and the start of the green light at another junction, as presented in Figure 4. The offset defines the movement of traffic along a major road, also referred to as "progression." It is very important to observe and fine-tune an offset system in order to plan for real traffic speeds and conditions to ultimately help reduce stops and slowing.

Table 4 below lays out the timing of traffic light synchronization along Jalan Bukit Gambier. This involved the distance between the traffic light, the time taken to drive between lights, and also the green light time.

Table 4. Traffic light timing

\begin{tabular}{|l|l|l|l|l|}
\hline Start & End & Distance & Drive time & Time reaching End Traffic \\
\hline 1st traffic & 2nd traffic & $400 \mathrm{~m}$ & 20sec & 8.00 a.m \\
\hline 2nd traffic & 3rd traffic & $1100 \mathrm{~m}$ & $60 \mathrm{sec}$ & $8.01 \mathrm{a} . \mathrm{m}$ \\
\hline 3rd traffic & 4th traffic & $500 \mathrm{~m}$ & $30 \mathrm{sec}$ & $8.01 \mathrm{a} . \mathrm{m}$ \\
\hline 4th traffic & 5th traffic & $700 \mathrm{~m}$ & $30 \mathrm{sec}$ & $8.02 \mathrm{a} . \mathrm{m}$ \\
\hline
\end{tabular}

\section{Conclusion}

This study took a closer look at all the processes involved in traffic light systems which involve the synchronization of traffic light timing and also the timing to clear vehicles in one go. This study also shows how important synchronized traffic timing can be to road users. Essentially, smooth traffic will be the end result of better traffic management. This can be accomplished through the implementation of synchronized traffic systems, especially in urban areas.

\section{References}

1. W.Wen (2008), Expert Systems with Applications, A dynamic and automatic traffic light control expert system for solving the road congestion problem, Volume 34, pp 2370 - 2381

2. Duo Sun, Rui Jiang \& Bing-Hong Wang (2010), Computer Physics Communications, Timing of traffic lights and phase separation in two-dimensional traffic flow, Volume 181, pp $301-304$

3. Takashi Nagatani (2009), Physics Letters A, Green-light paths in city traffic controlled by signals, Volume 373, pp 536 - 539

4. Masashi Sasaki \& Takashi Nagatani (2003), Physica A: Statistical Mechanics and its Applications, Transition and saturation of traffic flow controlled by traffic lights, pp 531 - 546

5. Yen-Liang Chen \& Hsu-Hao Yang (2003), European Journal of Operational Research, Minimization of travel time and weighted number of stops in a traffic-light network, Volume 144 , pp $565-580$

6. Gurcan Comert (2013), European Journal of Operational Research, Effect of stop line detection in queue length estimation at traffic signals from probe vehicles data, Volume 226, pp $67-76$ 